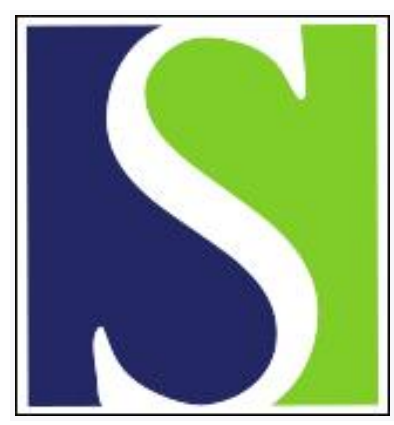

Scand J Work Environ Health 2005;31(6):474-478

https://doi.org/10.5271/sjweh.952

Issue date: 31 Dec 2005

Influence of childhood atopic dermatitis on future worklife

by Nyrén M, Lindberg M, Stenberg B, Svensson M, Svensson A, Meding B

Affiliation: Department of Occupational and Environmental Health, Norrbacka, S-171 76 Stockholm, Sweden. miruna.nyren@sll.se

The following article refers to this text: 2019;45(5):450-457

Key terms: childhood atopic dermatitis; consequences; eczema; exposure; future worklife; hand eczema; occupation; population-based study

This article in PubMed: www.ncbi.nlm.nih.gov/pubmed/16425589 


\title{
Influence of childhood atopic dermatitis on future worklife
}

\author{
by Miruna Nyrén, MD, ${ }^{1}$ Magnus Lindberg, MD, ${ }^{1}$ Berndt Stenberg, MD, ${ }^{2}$ Margareta Svensson, MD, ${ }^{1}$ Åke \\ Svensson, MD, ${ }^{3}$ Birgitta Meding, MD ${ }^{4}$
}

\begin{abstract}
Nyrén M, Lindberg M, Stenberg B, Svensson M, Svensson Å, Meding B. Influence of childhood atopic dermatitis on future worklife. Scand J Work Environ Health 2005;31(6):474-478.
\end{abstract}

\begin{abstract}
Objectives The purpose of this study was to perform a population-based follow-up of people with childhood atopic dermatitis with respect to the possible influence on their worklife.

Methods Medical records of the school health care services in Stockholm, Sweden, were reviewed for people born between 1960 and 1969. Altogether 600 persons with signs of atopic dermatitis ("cases") and 600 matched controls without eczema ("controls") were identified. Of these people, 405 cases and 378 controls answered a postal questionnaire focusing on choice of job, occupational exposure, past and present skin disease, and change of job due to eczema.

Results The proportions of cases and controls in jobs with a high risk of hand eczema were similar, as was the exposure to water, detergents, chemicals, and hand washing. The self-reported cumulative prevalence of hand eczema was $42 \%$ for the cases and $13 \%$ for the controls $(\mathrm{P}<0.001)$. The 1 -year prevalence was $24 \%$ for the cases and $9 \%$ for the controls $(\mathrm{P}<0.001)$. Among the cases, $9 \%$ reported a change of job due to eczema compared with $2 \%$ of the controls $(\mathrm{P}<0.001)$. The corresponding proportions of sick leave were $10 \%$ and $2 \%(\mathrm{P}<0.001)$.

Conclusions In conclusion, a history of atopic dermatitis in childhood does not seem to influence the choice of job nor hazardous occupational skin exposure. It does, however, mean an increased risk for job changes, sick leave, and medical consultations, mainly due to the increased risk of hand eczema.
\end{abstract}

Key terms consequences; eczema; exposure; hand eczema; occupation; population-based study.

Atopic dermatitis is a chronic skin disease that generally starts in infancy and has a variable prognosis. It affects between $5 \%$ and $20 \%$ of children worldwide, and the incidence appears to be rising in most western societies (1). Several studies have shown that a history of atopic dermatitis in childhood involves an increased risk of hand eczema in adulthood (2-6). Childhood eczema is the most important predictive factor for hand eczema $(5,7)$. Unfavorable prognostic factors for hand eczema among skin atopics are persistent "body" eczema, dry or itchy skin, and eczema on the hands already during childhood (3).

Risk factors for hand eczema are, in addition to an atopic disposition, exposure to skin irritants (eg, water, detergents, and chemicals) and contact allergy. Hand eczema is the major occupational skin disease (8). It can cause great disability and has economic repercussions as it leads to chronic disease with long sick leave, change of job, and, in some cases, permanent disability pension $(4,9-11)$. The disease also affects health-related quality of life $(12,13)$. However, little is known about the impact of a common skin disease like atopic dermatitis on a person's worklife (14).

The aim of our study was to perform a populationbased follow-up of people with atopic dermatitis in childhood with respect to the possible influence on their worklife, the extent to which a history of atopic dermatitis is considered in the choice of career, and the efforts made to reduce skin irritant occupational exposure.

\section{Study population and methods}

\section{Study population}

Medical records from children born between 1960 and 1969 and examined in school health care in Stockholm were reviewed. School health care is compulsory, and the records should thus reflect the local population. People

Occupational and Environmental Dermatology, Stockholm County Council and Karolinska Institutet, Stockholm, Sweden. Department of Public Health and Clinical Medicine, Umeå University, Umeå, Sweden.

Department of Dermatology, Malmö University Hospital, Malmö, Sweden.

National Institute for Working life, Stockholm, Sweden.

Reprint requests to: Dr Miruna Nyrén, Department of Occupational and Environmental Health, Norrbacka, S-171 76 Stockholm, Sweden. [E-mail: miruna.nyren@sll.se] 
with medical records indicating atopic dermatitis were registered as cases. An experienced dermatologist (MS) reviewed all of the medical records. If any data making the diagnosis of atopic dermatitis uncertain was encountered, the person in question was excluded. The indications of atopic dermatitis used were notes in the school records by the examining physician, school nurse, or parents. The symptoms or findings suggestive of atopic dermatitis were, for example, itchy eczema in the flexural part of the arms or legs. As controls, people matched for age and gender and without notes on atopic dermatitis were selected.

Records from 1200 persons-600 cases and 600 controls-were selected for study. Current postal addresses were found for 1111 of this group. We obtained the addresses by submitting the personal registration numbers to the national registration authorities. Every Swede has a personal registration number from birth, and the numbers are included in all of their medical records. A questionnaire was mailed in 2001, and after two reminders 783 respondents (71\%), 405 (229 women and 176 men) cases and 378 (212 women and 166 men) controls had filled out and returned the questionnaire. The mean age for the respondents was 37 (range 31-42) years, and it was similar for the cases and controls.

To ensure the accuracy of the classification of the cases, a second dermatologist unaware of the previous classification reviewed 100 medical records. Agreement between the two classifiers was $98 \%$.

\section{Questionnaire}

The questionnaire included 22 questions (appendix). In the analysis, occupations involving wet work or other trauma-related influences are classified as high-risk occupations for hand eczema (6). All other occupations were designated low-risk occupations.

\section{Statistics}

For comparisons of the proportions, the chi-square test was used. The means were compared using the Student ttest. Confidence intervals for odds ratios were calculated using the test-based method (15). The study was approved by the Ethics Committee of the Karolinska Institutet, Stockholm.

\section{Results}

In this study, current occupation was classified as high risk for $16.6 \%$ (men $14.9 \%$, women $17.9 \%$ ) of the cases and $17.6 \%$ (men $12.7 \%$, women $21.4 \%$ ) of the controls $(\mathrm{P}=0.702)$. There were no statistically significant differences between the cases and controls with respect to any of the reported exposures (table 1). Hand washing was significantly more frequent among the women than the men for both the cases and the controls.

The reported occurrence of hand eczema is presented in table 2. Hand eczema was more common among the cases than among the controls (cumulative prevalence $41.8 \%$ versus $13.4 \%$ ) and more common among female cases than among male cases. For the cases with

Table 1. Reported occupational exposure to water, detergents, and chemicals and the frequency of hand washing for the cases $(\mathrm{N}=405)$ and controls $(\mathrm{N}=378)$.

\begin{tabular}{|c|c|c|c|c|c|c|}
\hline \multirow[t]{2}{*}{ Exposure } & \multicolumn{3}{|c|}{ Cases $^{a}$} & \multicolumn{3}{|c|}{ Controls $^{a}$} \\
\hline & $\begin{array}{l}\text { Men } \\
(\%)\end{array}$ & $\begin{array}{c}\text { Women } \\
(\%)\end{array}$ & Total & $\begin{array}{l}\text { Men } \\
(\%)\end{array}$ & $\begin{array}{c}\text { Women } \\
(\%)\end{array}$ & Total \\
\hline \multicolumn{7}{|c|}{ Water and detergents } \\
\hline$<1 / 2$ hour/day & 87.2 & 81.4 & 83.9 & $90.6^{b}$ & $78.1^{b}$ & 83.6 \\
\hline $1 / 2-2$ hour/day & 7.0 & 11.5 & 9.6 & $8.1^{\mathrm{b}}$ & $13.2^{b}$ & 11.0 \\
\hline$>2$ hour/day & 5.8 & 7.1 & 6.5 & $1.3^{b}$ & $8.8^{b}$ & 5.5 \\
\hline \multicolumn{7}{|l|}{ Chemicals } \\
\hline$<1 / 2$ hour/day & 91.9 & 96.4 & 94.5 & $88.8^{c}$ & $95.6^{c}$ & 92.6 \\
\hline $1 / 2-2$ hour/day & 5.2 & 2.2 & 3.5 & $5.6^{c}$ & $1.5^{c}$ & 3.3 \\
\hline$>2$ hour/day & 2.9 & 1.3 & 2.0 & $5.6^{c}$ & $2.9^{c}$ & 4.1 \\
\hline \multicolumn{7}{|l|}{ Hand washing } \\
\hline 1-10 times/day & $87.8^{d}$ & $69.3^{d}$ & 77.3 & $89.4^{\mathrm{e}}$ & $72.8^{e}$ & 80.1 \\
\hline 11-20 times/day & $9.9 d$ & $23.3^{d}$ & 17.5 & $8.8^{e}$ & $18.9 \mathrm{e}$ & 14.5 \\
\hline$>20$ times/day & $2.3^{d}$ & $7.5^{d}$ & 5.3 & $1.9^{e}$ & $8.3^{e}$ & 5.5 \\
\hline
\end{tabular}

a Cases versus controls: no statistically significant differences.

b Men versus women: water and detergents $P<0.01$.

c Men versus women: chemicals $\mathrm{P}<0.05$.

${ }^{d}$ Men versus women: $P<0.001$

e Men versus women: hand washing $P<0.001$.

Table 2. Reported occurrence of hand eczema and age at the onset of hand eczema for the cases ( $N=405)$ and the controls ( $N=378$ ).

\begin{tabular}{|c|c|c|c|c|c|c|c|c|c|}
\hline \multirow[t]{2}{*}{ Group } & \multicolumn{3}{|c|}{ Hand eczema "ever" } & \multicolumn{3}{|c|}{ Hand eczema in previous 12 months } & \multicolumn{3}{|c|}{ Age of onset (years) } \\
\hline & $\begin{array}{l}\text { Men } \\
(\%)\end{array}$ & $\begin{array}{c}\text { Women } \\
(\%)\end{array}$ & Total & $\begin{array}{l}\text { Men } \\
(\%)\end{array}$ & $\begin{array}{c}\text { Women } \\
(\%)\end{array}$ & Total & $\begin{array}{c}\text { Men } \\
\text { (mean) }\end{array}$ & $\begin{array}{l}\text { Women } \\
\text { (mean) }\end{array}$ & Total \\
\hline Cases & $34.1^{\mathrm{a}}$ & $47.8^{\mathrm{a}}$ & 41.8 & $18.8^{b}$ & $28.6^{b}$ & 24.3 & $14.7^{\mathrm{c}}$ & $18.9^{c}$ & 17.4 \\
\hline Controls & $12.4^{\mathrm{d}, \mathrm{e}}$ & $14.3^{\mathrm{d}, \mathrm{e}}$ & $13.4^{\mathrm{e}}$ & $7.5^{\mathrm{d}, \mathrm{f}}$ & $9.6^{\mathrm{d}, \mathrm{e}}$ & $8.7^{\mathrm{e}}$ & $23.4^{\mathrm{d}, \mathrm{f}}$ & $27.0^{\mathrm{d}, \mathrm{e}}$ & $25.6^{\mathrm{e}}$ \\
\hline
\end{tabular}

a Men versus women: hand eczema "ever" $P<0.01$.

${ }^{b}$ Men versus women: hand eczema in past 12 months $P<0.05$.

${ }^{c}$ Men versus women: age of onset $P<0.05$.

${ }^{d}$ Men versus women: no statistically significant differences.

${ }^{\text {e }} \mathrm{P}<0.001$ for the differences between the cases and controls.

$f P<0.01$. 
Table 3. Reported consequences of eczema for the cases $(\mathrm{N}=405)$ and controls $(\mathrm{N}=378)$.

\begin{tabular}{|c|c|c|c|c|c|c|}
\hline \multirow[t]{2}{*}{ Consequence } & \multicolumn{3}{|c|}{ Cases } & \multicolumn{3}{|c|}{ Controls } \\
\hline & $\begin{array}{l}\text { Men } \\
(\%)\end{array}$ & $\begin{array}{c}\text { Women } \\
(\%)\end{array}$ & Total & $\begin{array}{c}\text { Mena } \\
(\%)\end{array}$ & $\begin{array}{c}\text { Women a } \\
(\%)\end{array}$ & Total \\
\hline Medical consultation & $33.5^{b}$ & $51.1^{\mathrm{b}}$ & 43.5 & $16.6^{c}$ & $14.6^{c}$ & $15.5^{c}$ \\
\hline Sick leave (>7 days) & $6.3^{d}$ & $12.3^{d}$ & 9.7 & 2.5 & $1.5^{c}$ & $1.9^{c}$ \\
\hline Change of job & $5.7^{\mathrm{e}}$ & $11.5^{\mathrm{e}}$ & 8.9 & 2.5 & $1.4^{\mathrm{c}}$ & $1.9^{\dagger}$ \\
\hline
\end{tabular}

a Men versus women: no statistically significant differences.

b Men versus women: medical consultation $\mathrm{P}<0.001$.

c $P<0.001$ for the differences between the cases and controls.

d Men versus women: sick leave $P<0.05$.

${ }^{\mathrm{e}}$ Men versus women: change of job $\mathrm{P}<0.05$.

f $\mathrm{P}<0.01$ for the differences between the cases and controls.

high occupational exposure (water and detergents or chemicals more than 2 hours/day or hand washing more than 20 times/day), the cumulative prevalence of hand eczema was $63 \%$ versus $40 \%(\mathrm{P}<0.01)$ for the less-exposed cases. The mean age at the onset of hand eczema was 17.4 years for the cases and 25.6 years for the controls $(\mathrm{P}<0.001)$. Hand eczema during the previous 12 months was significantly more frequent among the cases than among the controls, and more prevalent among the women than the men in the case group. Altogether 94 cases reported eczema on their hands in childhood. A total of $52 \%$ of them reported hand eczema during the previous 12 months; the corresponding proportion for the cases without eczema on the hands in childhood was $17 \%(\mathrm{P}<0.001)$.

The odds ratio for hand eczema morbidity "ever" among the cases compared with "ever" among the controls was 4.6 (95\% CI 3.2-6.6). However, for people reporting childhood eczema in the questionnaire (ie. recalling having had atopic dermatitis in childhood) the odds ratio was 6.7 (95\% CI 4.7-9.5) when compared with those reporting no childhood eczema in the questionnaire. This finding indicates a higher risk of hand eczema among the participants recalling atopic dermatitis in childhood.

The results concerning reported medical consultations, sick leave, and change of job due to eczema are shown in table 3. Medical consultations for eczema were almost three times as common among the cases as among the controls. Among the cases, the women reported more consultations than the men. Sick leave of $>7$ days for eczema was more frequent among the cases than among the controls. No association was found between sick leave and medical consultations and selfreported exposure or type of occupation. A change of job due to eczema was more common in the case group, $8.9 \%$ versus $1.9 \%$ for the controls. Of the 36 cases (26 women and 10 men) that changed jobs, 14 worked in health care, 12 had jobs in catering, 5 were employed in industry, and 5 worked in occupations not classified as high risk for hand eczema. This last group included 2 shop assistants, 1 chemist, 1 journalist, and 1 in an unspecified outdoor job.

\section{Discussion}

Atopic skin disease is a common condition, but its influence on the future worklife of a person has been given very little attention. Our study sought to shed light on the influence of atopic dermatitis on occupation and skin exposure and the risk of hand eczema and its consequences among skin atopics and control persons without atopic skin disease.

In our study the proportion of persons working in jobs with a high risk of hand eczema was similar for those with and without childhood atopic dermatitis, and the reported exposure to water, detergents, chemicals, and hand washing was equal between the groups. This finding indicates that childhood eczema may not have been considered in the choice of career. Occupational counseling focusing on the risk of hand eczema for atopic schoolchildren, or compliance with the advice, may have been insufficient. However, the role of atopic dermatitis as a risk factor of hand eczema was incompletely known before the 1980s.

Our findings are in accordance with the results of previous studies showing that a history of atopic dermatitis triples the risk of developing hand eczema $(5,6$, 16). A recent study showed that the association between atopic dermatitis and the incidence of hand eczema is restricted to ages below 30 years (17). The reported age of onset for hand eczema differed between the cases and controls, with earlier onset occurring for the cases. It is well known that the skin barrier function is altered in people with atopic dermatitis $(18,19)$. Exposure at the time of onset of hand eczema is of great interest but can only be investigated in detail in prospective studies. With eczema on the hands already in childhood, the 1year prevalence of hand eczema was as high as 52\%. This result is in accordance with the findings of earlier studies indicating that hand eczema before the age of 15 years among atopics is an unfavorable prognostic factor for adult hand eczema (3). The odds ratio for hand eczema morbidity was higher for people recalling childhood atopic dermatitis; this finding indicates that they may have suffered from more severe eczema in childhood.

In our study, hand eczema was more common among the women than the men among both the cases and controls, and this finding agrees with other epidemiologic data $(5,6)$. Women have more exposure to wet work in their early worklife than men (17). Wet work at home is also more frequent among women (16). 
The cases with the highest exposure had a higher prevalence of hand eczema; therefore exposure is of importance for the development of hand eczema. However, half of the cases in high-risk occupations for hand eczema and more than one-third of the cases with the highest exposure (water, detergents or chemicals $>2$ hours/day or hand washing $>20$ times/day) did not report hand eczema; therefore, as previously reported (2, 20 ), some persons with a history of atopic dermatitis may manage to stay free of dermatitis problems despite current risk factors.

Sick leave due to atopic dermatitis has not been extensively studied using medical record reviews or other registers. In a Finnish population, patients with atopic dermatitis did not go on sick leave more often than nonatopics, and most of the patients with atopic dermatitis had learned to work and live with their skin symptoms (14). In our study, sick leave, medical consultation, and change of job due to eczema were more common among the cases than the controls, with costly consequences both for the person in question and society. The decision to report sick is often multifactorial, as is the decision to change work, and probably depends not only on the severity of the disease, but also on the social security system, cultural background, and labor-market fluctuation.

Possibilities for preventing hand eczema among persons with a history of atopic dermatitis have been rarely studied. However, by choosing an adequate job with regard to the risk of hand eczema, the possibility to stay in that job probably increases. Many types of work are possible even if a person has hand eczema. Vocational guidance may be of value, but the impact of such an action should be studied. It is also of interest to determine how preventive advice should be given to influence people's behavior.

The diagnosis atopic dermatitis is usually based on many variables, including medical history, clinical signs, and symptoms. There is no internationally accepted disease definition for use in epidemiologic studies, nor is there a specific diagnostic test (21) giving the degree of variability to be accepted in the assessment of atopic dermatitis (22). This lack affects the interpretations of most studies. In our study, the diagnosis atopic dermatitis was assessed by an experienced dermatologist (MS) on the basis of data in medical records from school health care. The concordance between two reviewers, both experienced dermatologists, was high (98\%), and this agreement confirms the accuracy of the criteria used to diagnose atopic dermatitis. Our study was population-based, as all children attend school. The good response rate of $71 \%$ indicates that the results are representative. With the use of this design, we were able to avoid selection bias from using hospital records-the usual manner for this kind of study.
In conclusion, a history of atopic dermatitis in childhood does not seem to influence the choice of job nor hazardous occupational skin exposure. It does, however, mean an increased risk for job change, sick leave, and medical consultations, mainly due to the increased risk of hand eczema.

\section{Acknowledgments}

This study was supported by grants from the Edvard Welander and Finsen Foundations, the Asthma and Allergy Research Foundation and Stockholm County Council.

The skillful assistance of Gunborg Lindahl and Marie Gidlund and the review of medical records by Maria Karlsson are gratefully acknowledged.

\section{References}

1. Williams HC. Atopic dermatitis: the epidemiology, causes and prevention of atopic eczema. Nottingham (United Kingdom): Cambridge University Press; 2000. p 96-109.

2. Lammintausta K, Kalimo K. Atopy and hand dermatitis in hospital wet work. Contact Dermatitis 1981;7:301-8.

3. Rystedt I. Hand eczema and long-term prognosis in atopic dermatitis. Acta Derm Venereol Suppl (Stockh) 1985;117:159 .

4. Nilsson E. Individual and environmental risk factors for hand eczema in hospital workers. Acta Derm Venereol Suppl (Stockh) 1986;128:1-63.

5. Meding B. Epidemiology of hand eczema in an industrial city. Acta Derm Venereol Suppl (Stockh) 1990;153:1-43.

6. Meding B, Järvholm B. Hand eczema in Swedish adultschanges in prevalence between 1983 and 1996. J Invest Dermatol 2002;118:719-23.

7. Bryld LE, Hindsberger C, Kyvik KO, Agner T, Menne T. Risk factors influencing the development of hand eczema in a population-based twin sample. Br J Dermatol 2003;149:121420.

8. Dickel H, Kuss O, Blesius CR, Schmidt A, Diepgen TL. Occupational skin diseases in Northern Bavaria between 1990 and 1999: a population-based study. Br J Dermatol 2001; 145:453-62.

9. Forsbeck M, Skog E, Åsbrink E. Atopic hand dermatitis; a comparison with atopic dermatitis without hand involvement, especially with respect to influence of work and development of contact sensitisation. Acta Derm Venereol 1983;63:9-13.

10. Hogan D, Dannaker CJ, Maibach H. The prognosis of contact dermatitis. J Am Acad Dermatol 1990;23:300-7.

11. Meding B, Wrangsjö K, Järvholm B. Fifteen-year follow-up of hand eczema-persistence and consequences. Br J Dermatol 2004;152:975-80.

12. Wallenhammar LM, Nyfjäll M, Lindberg M, Meding B. Health-related quality of life and hand eczema-a comparison of two instruments, including factor analysis. J Invest Dermatol 2004;122:1381-9.

13. Skoet R, Zachariae R, Agner T. Contact dermatitis and quality 
of life: a structured review of the literature. Br J Dermatol 2003;149:452-6.

14. Lammintausta K, Kalimo K. Does a patient's occupation influence the course of atopic dermatitis? Acta Derm Venereol 1993;73:119-22.

15. Miettinen O. Estimability and estimation in case-referent studies. Am J Epidemiol 1976;103:226-35.

16. Nilsson E, Mikaelsson B, Andersson S. Atopy, occupation and domestic work as risk factors for hand eczema in hospital workers. Contact Dermatitis 1985;13:216-23.

17. Meding B, Järvholm B. Incidence of hand eczema-a population-based retrospective study. J Invest Dermatol 2004; 122:873-7.

18. Werner Y, Lindberg. Transepidermal water loss in dry and clinically normal skin in patients with atopic dermatitis. Acta
Derm Venereol 1985;65:102-5.

19. Werner Y. The water content of the stratum corneum in patients with atopic dermatitis: measurements with the Corneometer CM 420. Acta Derm Venereol 1986;66:281-84.

20. Rystedt I. Work related hand eczema in atopics. Contact Dermatitis 1985;12:164-71.

21. Svensson Å. Atopic dermatitis—epidemiology. In: Waersted A, Roksvoog PO, Beermann B, Strandberg K, editors. Treatment of atopic dermatitis. Oslo: Norwegian Medicines Control Authority; 1999. p 2:37-50.

22. Coenraads P-J, Diepgen TL. Risk for hand eczema in employees with past or present atopic dermatitis. Int Arch Occup Environ Health 1998;71:7-13.

Received for publication: 4 January 2005

\section{Appendix}

\section{Main questions used in the questionnaire}

Have you ever had hand eczema?

$\square$ yes $\square$ no

Have you had hand eczema on any occasion during the past 12 months?

$\square$ yes $\square$ no

Have you ever changed job or occupation because of eczema?

yes $\square$ no

What job or occupation did you leave?

Have you ever been on sick leave (minimum 7 days) because of eczema?

yes no

Have you ever, after the age of 15 years, consulted a doctor because of eczema?

yes $\square$ no

What is your present job or occupation?

Are your hands, at work, exposed to water and detergents?

$<1 / 2$ hour/day

$1 / 2-2$ hours/day

$>2$ hours/day

Are your hands, at work, exposed to chemical products (eg, paint, glue, solvents, oils, etc)?

$<1 / 2$ hour/day

$1 / 2-2$ hours/day

$>2$ hours/day

How many times per day, on the average, do you wash your hands?

1-10 times/day

$11-20$ times/day

$>20$ times/day 